\title{
PROCEEDINGS OF THE CLL'B.
}

The 255th regular meeting of the Cambridge Entomological Club was helel in the rooms of the Appalachian Mountain Club on Tuesday evening. March 20. Igor, with fifteen members present. In the absence of the President, Mr. Emerton occupied the chair. Mr. Frost was elected secretary pro tem. Realing of the minutes of the previous meeting postponed.

The subject of "Winter Collecting" was opened by Mr. Emerton and several undetermined species of small insects exhibited. Mr. Sampson said he had tried his light during the warm weather of January and had seen one moth that was attracted by it. The remarks finally drifted into a discussion on the liberation or ennergence of Lepicloptera during the winter months. The fresh and unrubbed condition of many captured specimens was used ai an argument in favor of the latter theory.

Mr. Kincaid exhibited a box of Coleoptera that he had collected ruring a six weeks stay at the Bermulas and remarked on the scarcity of the insects of this order on those islands. He said that many of the specimens exhibited were rare and some new to the fauna of the Bermulas.

Mr. C. A. Frost presented a paper on the alder weevil, Attclubus rhois Doh., and its parasite, containing his investigations of their habits, and the methor of constructing the nest or egg roll.

The rest of the evening was given over to informal conversation and an examination of the collection of spiders in alcohol and the models of different kinds of webs that lad been placed on public exhibition in the rooms by Mr. Emerton.

C. A. Frost, Sec. pro tem.

The 256 th regular meeting of the Cambridge Entomological Club was held in the rooms of the Applachian Mountain Club on Tuesday evening. April I7. 1906, with thirteen members and one visitor present. President Field in the chair. Records of previous meetings read and approved.

The President announced the death of the Treasurer of the Club, Mr. Roland Hayward, and appointed Messrs. Johnson. Newcomb and Emerton to draw up an expression of regret to be entered on the records. The committee presented the following statement which was accepted by the Club:

"It is with deep) regret that we record the death of Roland Hayward, for twenty-seven years a member of the Club and of late its Treasurer, who 
died at his home in Milton on April II, 1906. He made a special study of the Coleoptera. He had contributed many papers upon the order and at the time of his death was engaged upon a monograph of the genus Amara. The Club herehy expresses its high esteem for Mr. Hayward as a brother entomologist and its keen sense of loss at his untimely death."

Mr. Bowditch was elected Treasurer to fill the vacancy caused by the death of Mr. Hayward; and Mr. lirost was elected Secretary in place of Mr. Clark, resigned. Mr. Andrew J. Lloyd of Boston and Mr. W. T. M. Forbes of Anherst were unanimously elected to active membership.

Mr. Emerton explained the purpose of the organization of the Federation of Natural History Societies and read a draft of the By-Law's. Mr. Denton was elected to represent the Club at the meeting of the delegates in Boston on April 28, 1906 .

Mr. Titus, employed by the Division of Entomology at Washington, D. C . and Secretary of the Wishington Entomological Society, spoke briefly on the work of examining and caring for the imported parasites of the Brown-tail and Gyps! moths at Lynnfield, Mass. He said that many European species of spider, were appearing from the Lrown-tail nests, and that they wonld be liberated along with the primary parasites.

Ir Denton exhibited a specinen of Rhcscynthus scmialba from Central Africa, a large beatuful moth which. so far as he knew, was represented by only one other specimen in the country.

Dr. Russell exhibited photographs of some remarkable examples of the webs of trchips ccrasicorana that occurred in Winchendon several years ago. He also showed a fine series of the moth with two species of Hymenopterous and two species of Dipterous parasites. For the New England collection, he had two boxes of specimens of the genus Apatela (Acronycta) which were taken at Winchendon, Mass.

Ir Newcomb, who has been making automobile trips with the Superintendent for Suppressing the Gypsy and Brown-tail moths, spoke very highly of the work that is being done by the employees and the men in charge.

After that, informal conversation and adjournment.

C. A. Frost, Secreiary. 

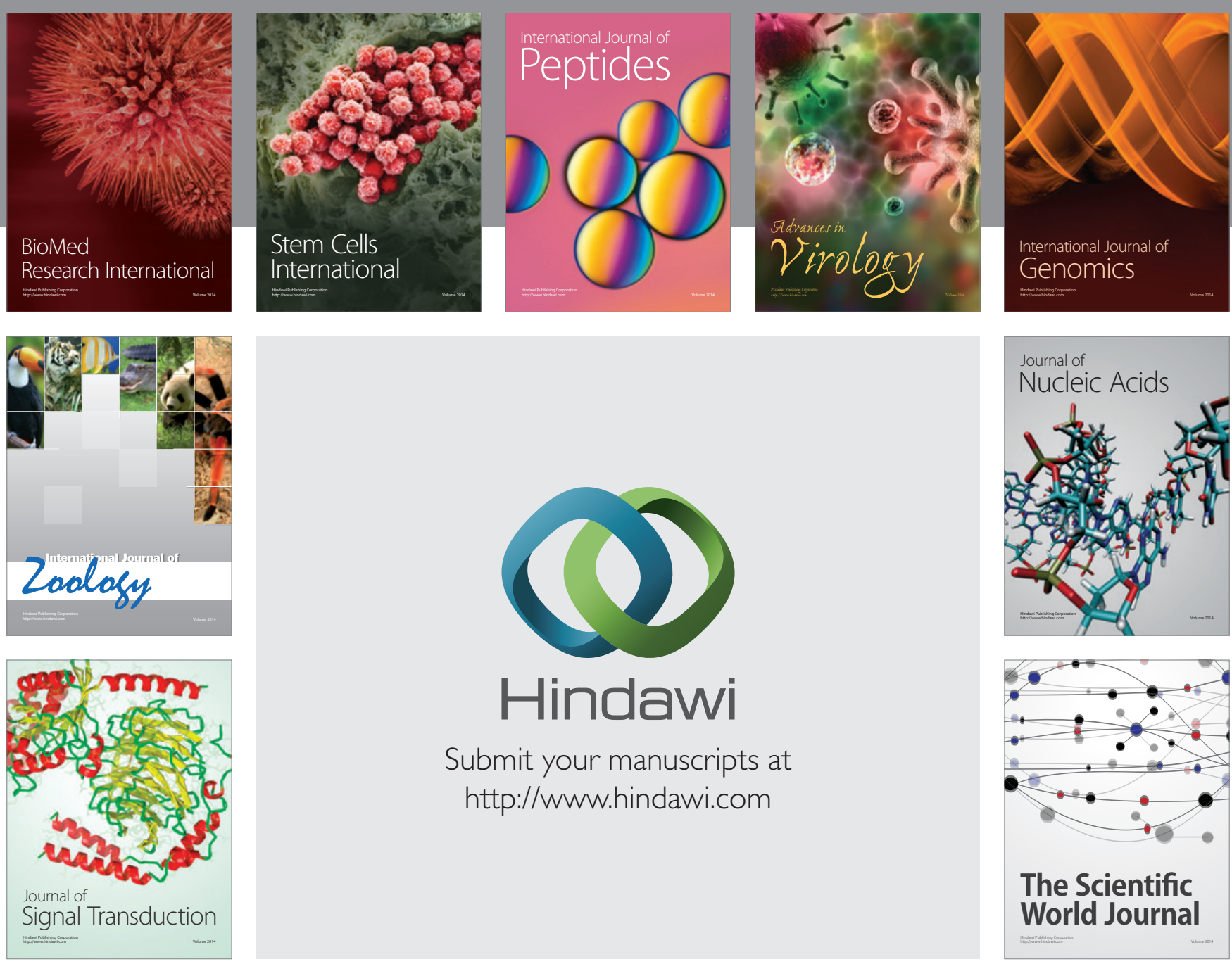

Submit your manuscripts at

http://www.hindawi.com
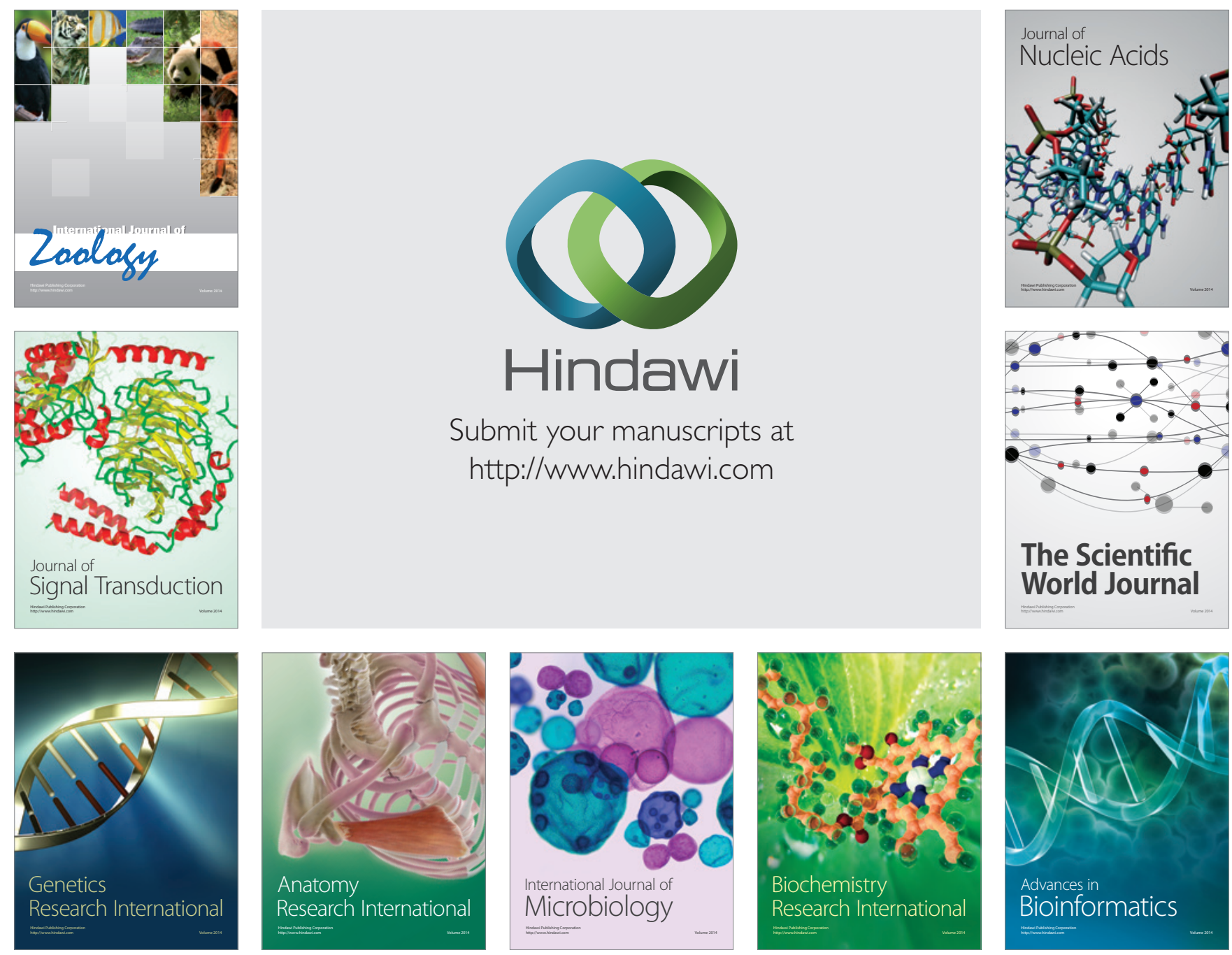

The Scientific World Journal
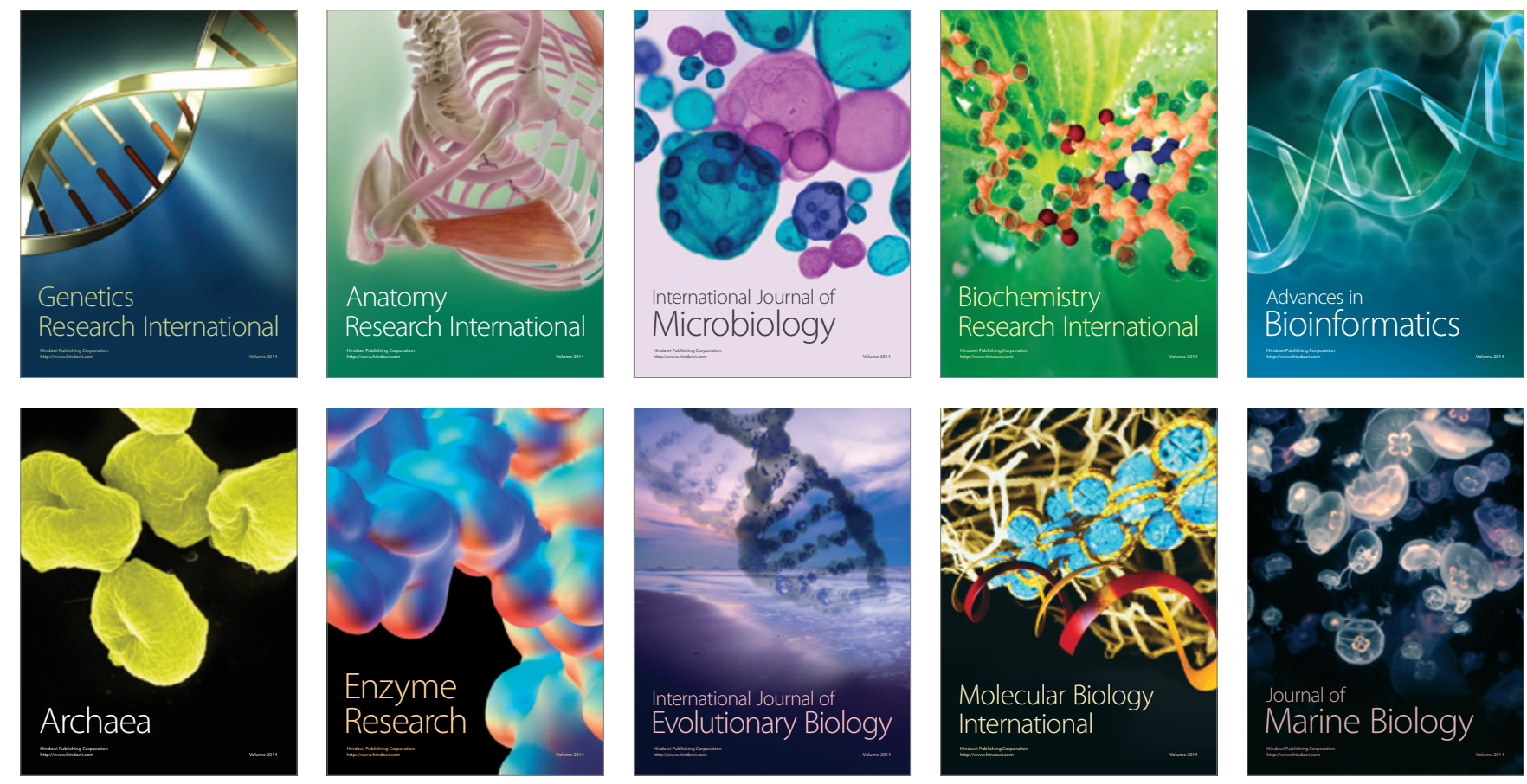